\title{
Correction to: Waterjet machining and research developments: a review
}

\author{
Xiaochu Liu ${ }^{1,2,3} \cdot$ Zhongwei Liang $^{1,2,3} \cdot$ Guilin Wen $^{2} \cdot$ Xuefeng Yuan ${ }^{3}$ \\ Published online: 23 March 2019 \\ (C) Springer-Verlag London Ltd., part of Springer Nature 2019
}

\section{Correction to: The International Journal of Advanced Manufacturing Technology https://doi.org/10.1007/s00170-018-3094-3}

The original version of this article contained several mistakes.

1. The origin of Fig. 1 was provided from the following literature:

[1] Matúš M., Ján P., Alexander H., Mária T., Kamil Ž.. (2016) A Review of Research on Water Jet with Slurry Injection. Procedia Engineering 149: 333-339.

[2] Hloch S., Monka P., Krolczyk G., Kozak D., Samardzić I., Stoić A., Sedmak A., Chattopadhyaya S., (2015) Hydroabrasive Cutting: A Surface Structure Study. India: Victorious Publisers, ISBN 978-93-84224-30-1.

2. Fig. 39 Microtopography of the AWJ-machined surface with specified influence factor values [164] has been corrected to: Microtopography of machined surface with specified factor values [164], furthermore [164] should be corrected as: Ján C., Sergej H., Petr H., Miroslav G., Dagmar K., František B.,

The online version of the original article can be found at https://doi.org/ 10.1007/s00170-018-3094-3

Zhongwei Liang

lzwgzhu@126.com; liangzhongwei@gzhu.edu.cn

1 Guangdong Engineering and Technology Research Centre for Strengthen Grinding and High-Performance Micro\Nano machining, Guangzhou University, Guangzhou 510006, People's Republic of China

2 School of Mechanical and Electrical Engineering, Guangzhou University, Guangzhou 510006, People's Republic of China

3 Advanced Institute of Engineering Science for Intelligent Manufacturing, Guangzhou University, Guangzhou 510006, People's Republic of China
Dušan M., Dominika L.. (2016) Hydro-abrasive disintegration of alloy Monel K-500-the influence of technological and abrasive factors on the surface quality. Procedia Engineering 149: 17-23.

3. The reference citation in Fig. 38 should be corrected to [163].

4. [165] has been corrected to: Milena K., Michal $\breve{R}$., Jan V., Sergej H., Milan K.. (2012) Determination of technologically optimal factors of modulated waterjet. Int J Adv Manuf Technol. 60:173-179.

The corresponding sentences citing literature [165] should be corrected as:

Sergej H. et al. [165] deals with two methods of determination of technologically optimal factors of a hydrodynamic resonance system leading to the acquiring of maximal fundamental frequency, amplitude, pressure, and energy of oscillations of a liquid jet.

6. [249] should corrected to: Vincent P., Pavol H., Sergej H., Hakan T., Jan V. (2012), Vibration emission as a potential source of information for abrasive waterjet quality process control. Int J Adv Manuf Technol. 61(1-4): 285-294.

7. [286] should be updated as: Li Ping Cao, Shi Liu, Yao Song Huang, Qian Liu, Zhi Hong Li. (2012) Study of high-pressure waterjet characteristics based on CFD simulation, Applied Mechanics and Materials, 224: 307-311.

8. [298] should be updated as: S.-T. Liu. (2006) Optimization of a machining economics model with fuzzy exponents and 
coefficients. International Journal of Production Research. 44(15): 3083-3104.

9. [348] should be updated as: Yu. V. Loktiushina, A.N.Semko. Influence of the working fluid properties on water jet cannon efficiency. Computers \& Fluids. 2014, 103(11): $166-174$.

10. In Fig. 75, the original sentence "Erosion resistance for waterjet tooling and abrasive sharpening [249]" should be corrected into "Erosion resistance for waterjet tooling and abrasive sharpening [242]".

11. The origin of Fig. 78 was corrected to: [249].

Publisher's note Springer Nature remains neutral with regard to jurisdictional claims in published maps and institutional affiliations. 